\title{
The Dynamics of Share-Price Formation
}

\section{J. Tinbergen}

The Review of Economic Statistics, Vol. 21, No. 4. (Nov., 1939), pp. 153-160.

Stable URL:

http://links.jstor.org/sici?sici=0034-6535\%28193911\%2921\%3A4\%3C153\%3ATDOSF\%3E2.0.CO\%3B2-U

The Review of Economic Statistics is currently published by The MIT Press.

Your use of the JSTOR archive indicates your acceptance of JSTOR's Terms and Conditions of Use, available at

http://www.jstor.org/about/terms.html. JSTOR's Terms and Conditions of Use provides, in part, that unless you have obtained prior permission, you may not download an entire issue of a journal or multiple copies of articles, and you may use content in the JSTOR archive only for your personal, non-commercial use.

Please contact the publisher regarding any further use of this work. Publisher contact information may be obtained at http://www.jstor.org/journals/mitpress.html.

Each copy of any part of a JSTOR transmission must contain the same copyright notice that appears on the screen or printed page of such transmission.

JSTOR is an independent not-for-profit organization dedicated to and preserving a digital archive of scholarly journals. For more information regarding JSTOR, please contact support@jstor.org. 


\section{THE DYNAMICS OF SHARE-PRICE FORMATION}

\section{THE RÔLE OF SHARE PRICES IN THE BUSINESS CYCLE}

$\mathbf{I}^{\mathrm{s}}$ $\mathrm{N}$ a recent investigation which the author has made for the League of Nations Secretariat, it was found that share prices seem to have exerted a considerable influence on the course of the American cycle beginning in r924 and having its boom year in 1929. The chief reason for this influence may be summarized briefly as follows: (a) Share prices have an influence on the ease with which capital issues may be floated and therefore on investment activity in general; $(b)$ the rate of increase in share prices seems to have an influence on consumption, especially by those making capital gains. These influences have been investigated in the forthcoming League of Nations publication and will not be treated in detail now, but it may be seen from this brief indication that the formation of share prices seems to be important in the explanation of some business-cycle phenomena. This is the justification for the present paper, which deals only with that price formation. ${ }^{1}$

\section{STATIC FACTORS IN SHARE- PRICE FORMATION}

Some preliminary remarks on the particular qualities of shares as a type of commodity may first be made. Contrary to most commodities, price fluctuations of shares do not seem to be caused by violent changes in the scarcity of shares, since the number of shares present at each moment changes only very slowly and continuously, owing to the long average lifetime of shares. These price fluctuations, however, must be understood as a consequence of changes in the quality of the commodity called shares. In fact, whereas most of the ordinary commodities have a constant attractiveness for most people and in any case for the last consumer, the attractiveness of shares is subject to heavy changes. This attractiveness has two quite distinct aspects: first of all, a share yields to its owner an income, and secondly, it may

\footnotetext{
${ }^{1}$ The object is therefore the same as that chosen by Dr. O. Donner in his excellent study "Die Kursbildung am Aktienmarkt," Vierteljahrshefte zur Konjunkturforschung, Sonderheft 36 (Berlin, r934).
}

yield a price gain or price loss, as soon as its owner sells it. It will be clear that the relative importance of these two aspects changes from case to case. If the share does not change hands very often, the first aspect will be the most important one. This is the case if its owner is an investor. If the share changes hands often, the second aspect is more important. This is the case if its owner is a speculator. In reality mixed forms of attitude may of course be present, but it is an easy instrument of analysis, if one makes this distinction clearly.

These preliminary remarks being made, we may, as a first step toward the explanation of share prices, recall a very simple law, which is often quoted to illustrate share-price formation. This law, which we may call the simple static law, holds that share prices vary proportionally with dividends and, inversely, proportionally with the rate of interest, for which the long-term rate may be taken. To quote a simple example: If at some moment the interest rate is 4 per cent and the share we consider yields a dividend of Io per cent, then its price, according to this law, should be 250 per cent of its nominal value. The simple static law is, however, only valid under special conditions, viz., $(a)$ the market consists only of investors, no speculators are present; $(b)$ the dividend is assumed to be constant through time, or at least expected to be so. As soon as one of these two conditions is not fulfilled, the price of the share may be different from 250 . Suppose, e.g., that the dividend is expected to fall next year, then it will be clear that the price will be lower than 250 , and the contrary if the dividend is supposed to rise. This will be valid even if the first condition, viz., that no speculators are present in the market, still remains valid. If in addition speculatively-minded people contribute to the formation of the share price, then the expectation of rising dividends may lead to the expectation of capital gains and may itself again influence the share price. Thus the simple static law will not be very often fulfilled in reality.

As a second step in the explanation of share prices, we may mention a generalized static law, describing the price formation in cases where only the first of the two above-mentioned conditions is fulfilled. In this case, the dividend 
is assumed to be variable through time, and it is to be expected that share prices will not vary as much as dividends. If dividends are currently at a very high value, the market will be aware of the possibility that future dividends will be lower and therefore the price will be lower than that following from the simple static law. When at another moment dividends are exceptionally low, the expectation will be rather general that future dividends will be higher, and thus the price will be higher than that following from the simple static law. Assuming that expectation on future dividends will always tend to some normal mean value, one reaches the conclusion that under such conditions share prices will still depend on dividends, but will vary not proportionally but less than proportionally. This we call the generalized static law.

As to the influence of the interest rate on share prices, this generalized static law may be given two different forms: First one could assume that share prices still vary in inverse proportion to interest rates; and secondly one could assume that share prices still depend on the ratio of dividends to interest rates. This would mean that, also in relation to interest rates, share prices would vary less than they do under the simple static law. The first case will appear if variations in the interest rate are considered as definitive; in other words, if at any moment everybody expects the interest rate to remain at the current level. The second case, on the other hand, will be present if interest variations are considered as temporary and future interest rates will be nearer some normal mean value than the current rates. In an earlier paper, ${ }^{\mathbf{1}}$ I showed that the generalized static law is fulfilled for a number of different shares, and in particular it was found that, if dividends changed by ro per cent of their initial value, the corresponding change of share prices was in most cases about 5 per cent. This I interpreted by saying that the representative investor seemed to expect that future dividends would always be half as near to normal dividends as the actual ones observed. I did not in that paper pay any attention to the possibility of the above-mentioned two different types of the generalized static law, and in fact

\footnotetext{
1 "The Notions of Horizon and Expectancy in Dynamic Economics," Econometrica, I (I933), pp. 247-64.
}

I restricted myself to the second type of relation discussed above.

\section{A DYNAMIC THEORY OF SHARE- PRICE FORMATION}

As has been said before, the generalized static law is valid only in the case where speculators have no perceptible influence on the formation of share prices. We shall now consider a case where this is no longer so. This means that the second aspect of what we call the attractiveness of shares comes into operation. Share prices will be influenced not only by dividends and interest rates, but also by the expected price gains or price losses, resulting from a change in prices of the share. These expected price gains or losses will depend on various types of factors, which may be subdivided under two headings: $(a)$ accidental disturbances from the outside; (b) systematic forces, depending on past experience of the owner or buyer of the share in question.

One of the most natural assumptions about this second type of force is that the attractiveness of the share will be the greater, the greater has been the rise in prices some time before. ${ }^{2}$ This assumption seems to reflect in a simple way what is commonly known as the speculative mood in the stock market, and it is on this assumption that we formulate the following dynamic law of share-price formation: share prices are governed by three factors, viz., $(a)$ dividends, (b) interest rates, $(c)$ the rate of increase in the prices themselves some time before. Using algebraic symbols, this amounts to saying that share prices $(n)$ are determined by the following formula:

$$
n=v_{1} d+v_{2} m+v_{3} \dot{n}
$$

where $v_{1}, v_{2}$, and $v_{3}$ are constant coefficients, $d$ represents dividends, $m$ represents interest rates ${ }^{3}$ and $\dot{n}$ represents the rate of increase in $n$ itself. Of course, the assumption that this

\footnotetext{
${ }^{2}$ Of course, other considerations will also play a rôle. As far as expectations are based on the actual level of prices - in distinction from the rate of increase in prices they are already included in our formula, presented below, since they add a term depending on $n$, which may, however, be combined with the left-hand side of the equation. This is true independently of the direction of the influence of $n$ on expectations.

${ }^{3}$ All these variables are assumed to be measured as deviations from average over the period studied.
} 
function is linear is meant only as a first trial, and it may follow from statistical observation that some other type of mathematical function is to be preferred. It would be difficult, however, to say this beforehand. Much attention is given to this question in the League of Nations publication referred to above, but for the present paper the question is of less importance. Therefore we shall not go into this now. The third factor mentioned in our dynamic law may exert its influence after some time has elapsed or, in other words, $\dot{n}$ may show a lagged influence. On the one hand, one could argue that speculation is a business taking only little time and that for this reason only small time-lags should be expected to exist between the rate of increase in share prices and share prices themselves. On the other hand, however, one should not overlook the fact that the greatest influence of a speculative mood on share prices will develop only after the public has entered the market and not so much at moments when only insiders and professional speculators are buying; and there may be a considerable timelag between a rise in the share market and the corresponding entrance of the public in the market. Some indication of this point is yielded by the fact that about 50 per cent of incomes derived from the sale of assets in the United States are due to sales of assets held over two years. Although such sales are of course partly of a non-speculative nature, it would nevertheless follow that the lags involved in speculation may be longer than only a few months. In the following investigation the lag has therefore not been given any a priori value, but is simply determined from the statistical evidence. It turned out to be half a year in a number of cases and one year in other cases, which does not seem impossible after what was said above.

\section{STATISTICAL TESTS OF THE DYNAMIC LAW}

The dynamic law of share-price formation as described above has been tested for a number of countries and a number of periods. The testing has been made with the aid of multiple correlation calculations. The attempt has been made to find the coefficients $v_{1}, v_{2}$, and $v_{3}$ as in formula (I), which give a calculated value for share prices approximating as closely as possible the actual values observed statistically. The influence of dividends and interest rates (including the influence of expectations) has been assumed to be instantaneous, whereas the influence of the rate of increase in past prices has been assumed to be a lagged one, where the lag was determined from a graphical examination. In a number of cases we convinced ourselves that the changes in this lag did not influence our results too much. As a rule the coefficients $\nu_{1}$ and $\nu_{2}$ were considered to be independent of each other, and were determined separately; this may be called a free determination of the coefficients $v_{1}$ and $v_{2}$. Such a free determination may be a test between the two types of influence, which according to our generalized static law may be exerted by the interest rate (cf. section II). In some cases, however, where the regression coefficient found for $\nu_{2}$ seemed to be rather improbable, another type of calculation was also made. In these calculations it was assumed that the second form of the generalized static law was valid, and this type of determination may be called an a priori determination of the influence of interest rates.

All information about these types of calculations, about the statistical sources used, about the countries and periods studied, have been indicated in Tables I and 2. These tables, in addition, show the ratio the regression-coefficients found for $d$ and $m$ (dividends and interest rates) show to the values they should have according to the simple static law. The results of the calculations have in addition been represented in a standardized graphical form (see Charts I to 7) the principle of which is as follows: The first two curves are shown on the same scale, with the dotted curve representing the actual course of share prices (sometimes taken as the deviations from a nine-year moving average) and the full line representing the calculated value of share prices. Three ${ }^{1}$ other curves are shown, each representing the course of one of the terms of the regression equation (I). The calculated values of share prices indicated by the first full line are found by addition of the corresponding values of the lower curves. This enables one to find immediately which of the independent variables has

\footnotetext{
${ }^{1}$ In some cases, there are two or four, according to the number of independent variables.
} 
Table i. - The Explanation of Share-Price Fluctuations by Dividends, Long-Term Interest Rates, and the Rate of Increase in Share Prices, Lagged: Summary of Regression Coefficients Obtained

(Units: share prices, average over period studied $=100 ;$ dividends in per cent of nominal capital; long-term interest rate in per cent; rate of increase in share prices, same unit as corresponding share price index. No trend eliminations have been performed, except where the contrary is stated. Dividends are taken at moment of earning, not at moment of declaration or distribution.)

\begin{tabular}{|c|c|c|c|c|c|c|c|}
\hline \multirow{3}{*}{ Country } & \multirow{3}{*}{ Period } & \multicolumn{3}{|c|}{ Regression Coefricients 1} & \multirow{2}{*}{\multicolumn{2}{|c|}{$\begin{array}{l}\text { RATIO OF REGR. } \\
\text { CoEFF. }{ }^{1} \text { TO VAL- } \\
\text { UES REQUIRED } \\
\text { BX "SIMPLE } \\
\text { STATIC LAW" }\end{array}$}} & \multirow{3}{*}{ OBSERVATIONS } \\
\hline & & \multirow{2}{*}{$\begin{array}{l}\text { Divi- } \\
\text { dends } \\
(d)\end{array}$} & \multirow{2}{*}{$\begin{array}{c}\text { Interest } \\
\text { rate } \\
\left(m_{L b}\right)\end{array}$} & \multirow{2}{*}{$\begin{array}{c}\text { Rate of } \\
\text { increase } \\
\text { in share } \\
\text { prices } 2 \\
(\dot{n})\end{array}$} & & & \\
\hline & & & & & $\begin{array}{l}\text { Divi- } \\
\text { dends }\end{array}$ & $\begin{array}{c}\text { Interest } \\
\text { rate }\end{array}$ & \\
\hline United States & I9I9-I932 & 14 & 22 & $2.50\left(\frac{1}{2}\right)$ & $0.9 x$ & $0.9 I$ & Curvilinear infl. of $\dot{n}$ \\
\hline United States $^{3}$ & I $872-1895$ & 25 & - I9 & $0.43\left(\frac{3}{4}\right)$ & 0.54 & 1.00 & 4 \\
\hline United States $^{3}$ & I895-I9I4 & 20 & -36 & $0.36\left(\frac{3}{4}\right)$ & 0.64 & 1.52 & \\
\hline United Kingdom .. & I87I-I9IO & 5 & -25 & $0.33(\mathrm{I})$ & 5 & 0.72 & $\left\{\begin{array}{l}\text { Deviations from } 9 \text { yr. mov. averages } \\
\text { for all series }\end{array}\right.$ \\
\hline Germany & I870-I9I3 & $7.4^{\circ}$ & -32 & $-0.04\left(\frac{1}{2}\right)$ & 0.63 & 1.22 & \\
\hline Belgium $^{6}$. & I870-I894 & & -9 & $0.22\left(\frac{1}{2}\right)$ & 0.30 & 0.30 & Trend term included since dividend \\
\hline Belgium $^{6}$ & I895-I9I2 & 7 & $-\mathbf{r} 4$ & $0.5 \mathrm{I}\left(\frac{1}{2}\right)$ & 0.43 & 0.43 & figures are money amounts. \\
\hline Netherlands $^{6}$.. & I922-1937 & I9 & -26 & $-0 . \operatorname{II}\left(\frac{1}{2}\right)$ & 0.74 & 0.77 & Correlation only 0.95 \\
\hline Netherlands $^{6} \quad \ldots$ & I922-1937 & I6 & -4 & $\cdots$ & 0.64 & 0.13 & Correlation $0.98^{8}$ \\
\hline Netherlands ... & I922-1937 & $I 7$ & $-2 I$ & $\ldots$ & $0.7 x$ & $0.7 \mathrm{I}$ & Correlation $0.97^{8}$ \\
\hline Neth. East Indies ${ }^{6} \ldots$ & I922-1937 & 4.7 & -29 & $-0.2 \mathrm{I}(\mathrm{I})$ & $0.6 \mathrm{I}$ & 0.82 & Correlation only 0.93 \\
\hline Neth. East Indies ${ }^{6} \ldots$ & I922-I937 & 8.4 & -30 & $-0.49\left(\frac{1}{2}\right)$ & 1.05 & $\mathrm{I} .02$ & Correlation $0.98^{\circ}$ \\
\hline Neth. East Indies & I922-I 937 & 9.8 & -30 & $-0 . I_{7}(\mathrm{I})$ & $\mathrm{I} .22$ & 1.00 & Correlation $0.98^{\circ}$ \\
\hline
\end{tabular}

${ }^{i}$ Cases where the coefficients for dividends and interest rates have been given an $a$ priori ratio are printed in italics.

${ }^{2}$ Lags applied are in parentheses (in years); they are the lags giving the best correlations, estimated graphically.

${ }^{3}$ Railway shares only.

${ }^{4}$ I.e., the influence is assumed to be zero for values of the rate of increase in prices under 20 and linear for higher values.

${ }^{5}$ Since dividend figures are not available, profit figures were taken which cannot be expressed as a percentage of capital; in addition they also contain interest payments which do not affect their cyclical variations, but do affect their level.

${ }^{6}$ No charts are shown for these cases.

${ }^{7}$ Dividends not given as a percentage of capital, but in money amounts.

${ }^{8}$ Difference between American and Dutch share price index numbers included as additional variable; i.e., the correlation calculations have been made with the American index as an additional variable (and the charts have been drawn correspondingly), but afterwards the formula was transformed to one where the difference just quoted appeared as additional variable. In symbols: $n=\nu_{1} d+\nu_{2} m+\nu_{3} \dot{n}+\nu_{4} n_{\mathrm{USA}}$ was transcribed into $\left(\mathrm{I}-\nu_{4}\right) n=\nu_{1} d+\nu_{2} m+\nu_{3} \dot{n}+\nu_{4}\left(n_{\mathrm{OSA}}\right.$ $-n)$.

${ }^{\circ}$ Difference between Dutch and N. E. Indies share price index numbers included as additional variable, cf. note 8.

TABle 2.-Sources of Material Used

\begin{tabular}{|c|c|c|c|}
\hline Country & Share Prices & DIVIDENDS & INTEREST RATES \\
\hline United States, I919-1932 ... & 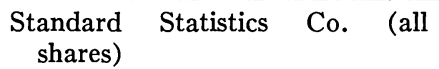 & Calculated by League of Nations & Standard Statistics \\
\hline United States, r872-r9r4 $\ldots$ & $\begin{array}{l}\text { Cowles, Common Stock Indexes } \\
\text { (Bloomington, r938) (Railway } \\
\text { shares) }\end{array}$ & Cowles, loc. cit. & Cowles, loc. cit. \\
\hline United Kingdom ..... & $\begin{array}{l}\text { London and Cambridge Economic } \\
\text { Service, Special Memorandum } \\
\text { No. } 37 \text { (Industrials) }\end{array}$ & $\begin{array}{l}\text { Bowley, Economic Journal, r9o4 } \\
\text { Stamp, British Inc. E Property }{ }^{1}\end{array}$ & $\begin{array}{l}\text { Statistical Abstract, } \\
\text { U. K., yield on } \\
\text { consols }\end{array}$ \\
\hline Germany $\ldots \ldots \ldots \ldots \ldots$. & $\begin{array}{l}\text { Institut für Konjunkturforschung, } \\
\text { Sonderheft } 36 \text { (Donner) }\end{array}$ & Donner, loc. cit. & Donner, loc. cit. \\
\hline Belgium .... & $\begin{array}{l}\text { Institut des Sciences Economiques, } \\
\text { Bulletin I } 936 / 37 \text { (Drappier), } \\
\text { p. } 39 \mathrm{I}\end{array}$ & Drappier, loc. cit. & Drappier, loc. cit. \\
\hline Netherlands and N. E. Indies & $\begin{array}{l}\text { Central Bureau of Statistics, } \\
\text { Maandschrift }\end{array}$ & Central Bureau of Statistics & $\begin{array}{l}\text { Central Bureau of } \\
\text { Statistics }\end{array}$ \\
\hline
\end{tabular}

${ }^{1}$ Figures for non-labor income ("profits"). 
Chart I.- "Explanation" of Share Price Index for THE U. S. A., I9I9-32

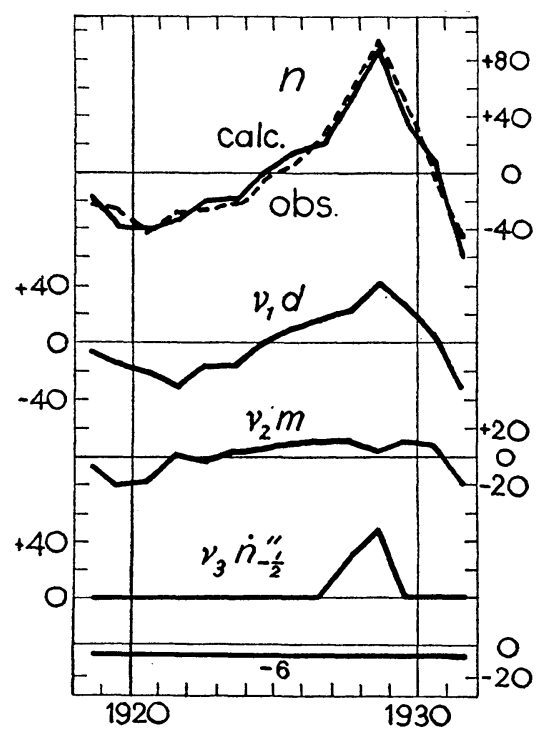

caused or contributed to a given change in a given year. All other information concerning the charts will be found in the tables. Annual figures have been used throughout since more frequent data on dividends are available in only a few cases. For the most important case, viz., that relating to the United States (post-war period) calculations with quarterly figures confirmed the results found with annual figures.

\section{RESULTS}

Looking at the charts one finds that our dynamic law seems to explain well most of the movements observed in share prices in the various countries and periods studied. This may also be seen from the high value of the correlation coefficients obtained. As to the coefficients found for dividends and interest rates, it may be said that most of them obey our generalized static law in that most of them are below the theoretical values yielded by the simple static law. It is only in the cases of the United States after the war and the Netherlands East Indies that this simple static law seems to be more or less closely approximated. In a number of cases the coefficients of the interest rate are very near to or even above the simple static law's values. This would mean that the first form given to the generalized static law would be near to real conditions for those cases. On the other hand, there are some cases where the regression coefficient found for the interest rate is much

Chart 3.- "Explanation" of Share Price Index FOR RAILWAYS IN THE U. S. A., I895-I9I4
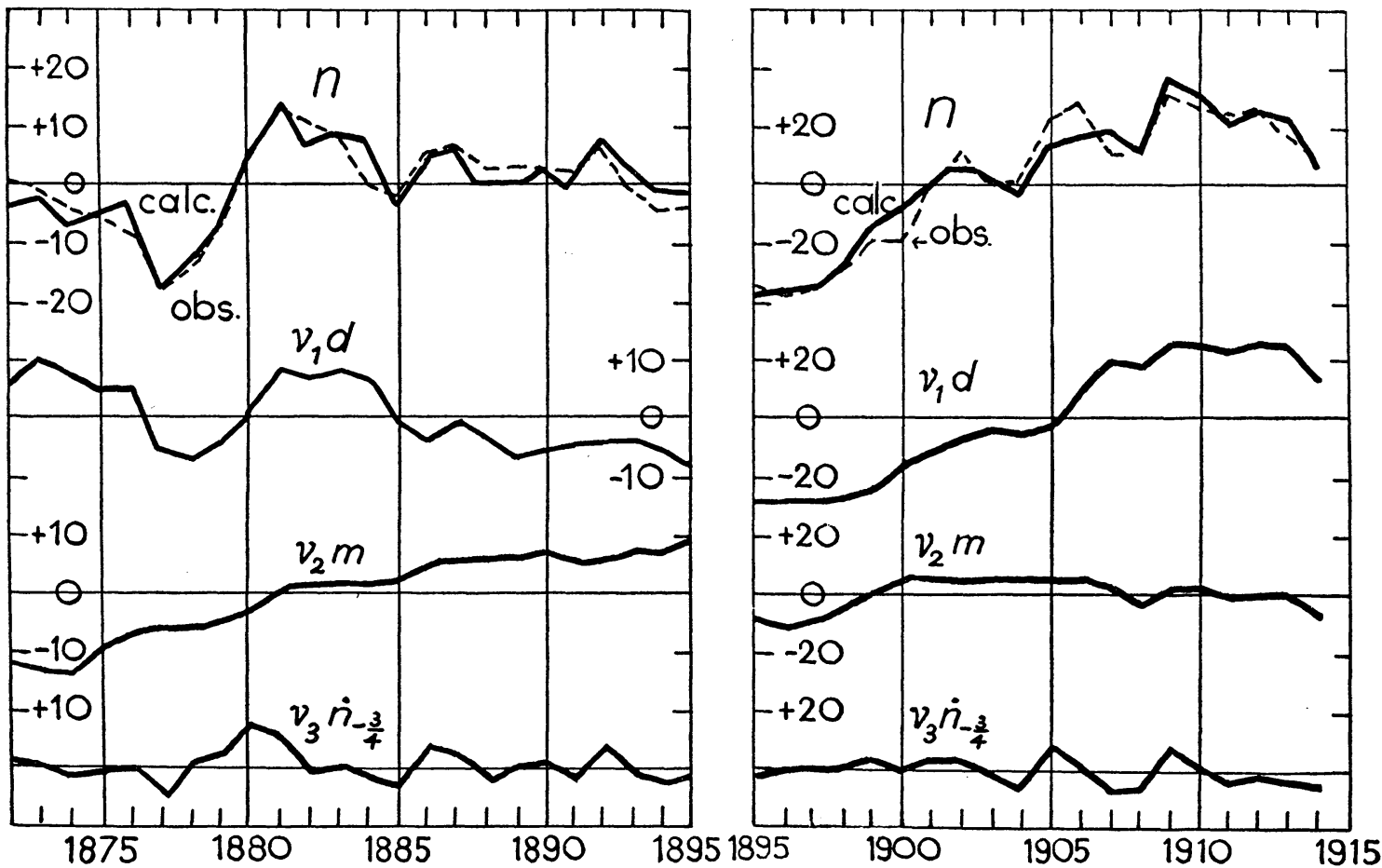


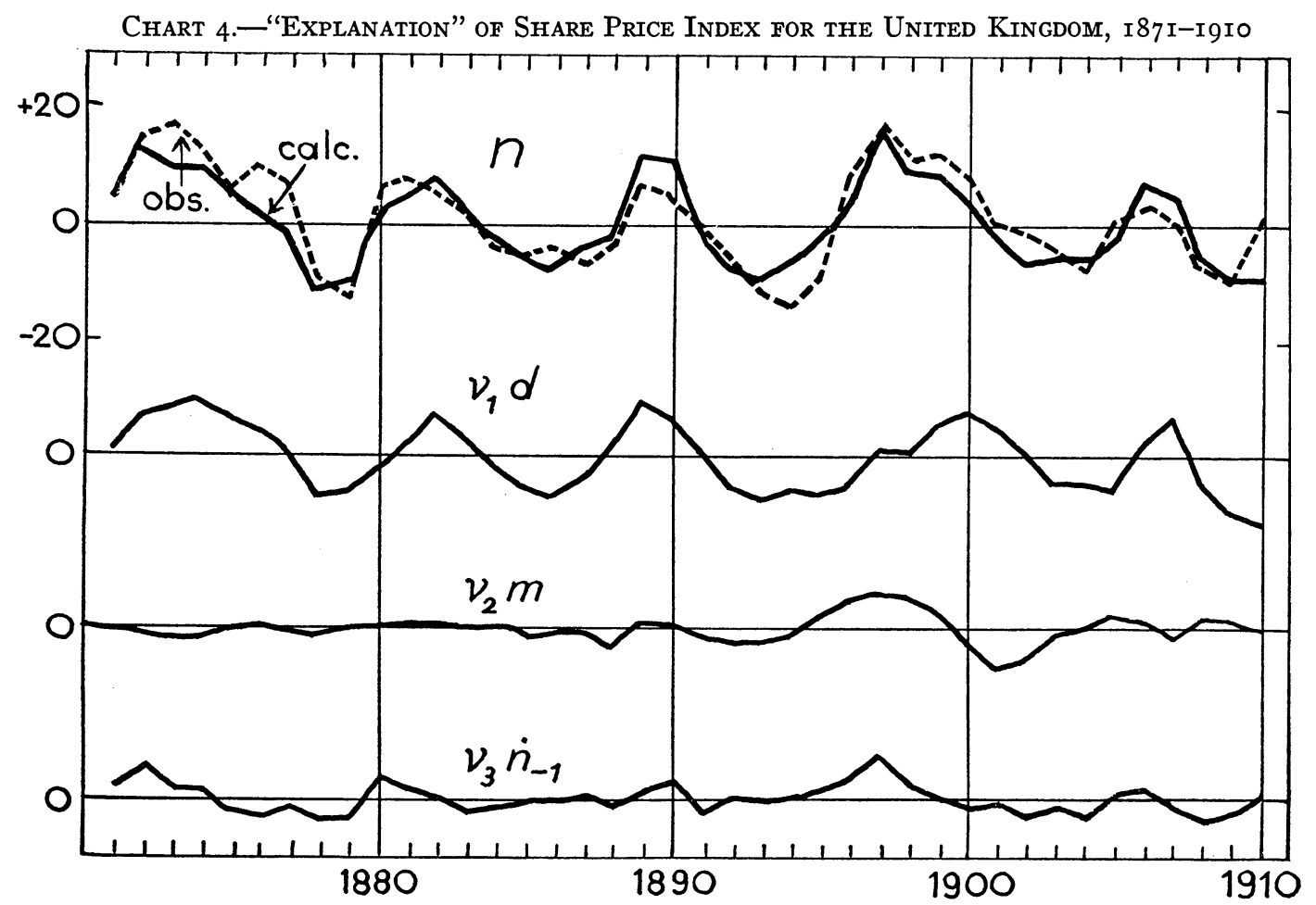

Chart 5.- "Explanation" of Share Price Index for Germany, i870-I9i3

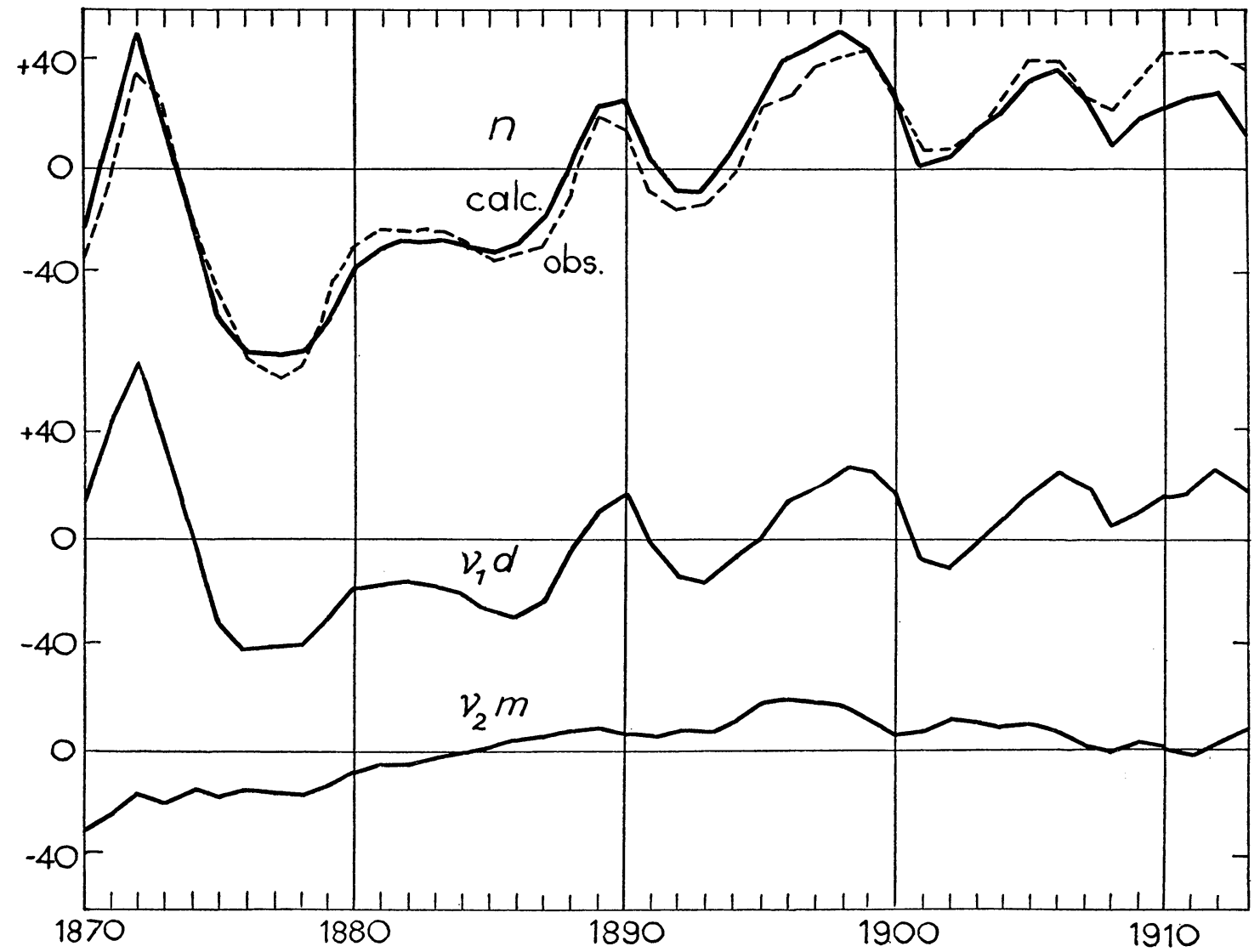


lower, which would point to the fulfilment of the second type of our generalized static law. At any rate, the differences between the various countries are in most cases only moderate. The same does not at all apply to the coefficients found for the rate of increase of share prices. These coefficients, which reflect the speculative mood of the public in the various periods and countries, are widely divergent. The highest value is found for the post-war period in the

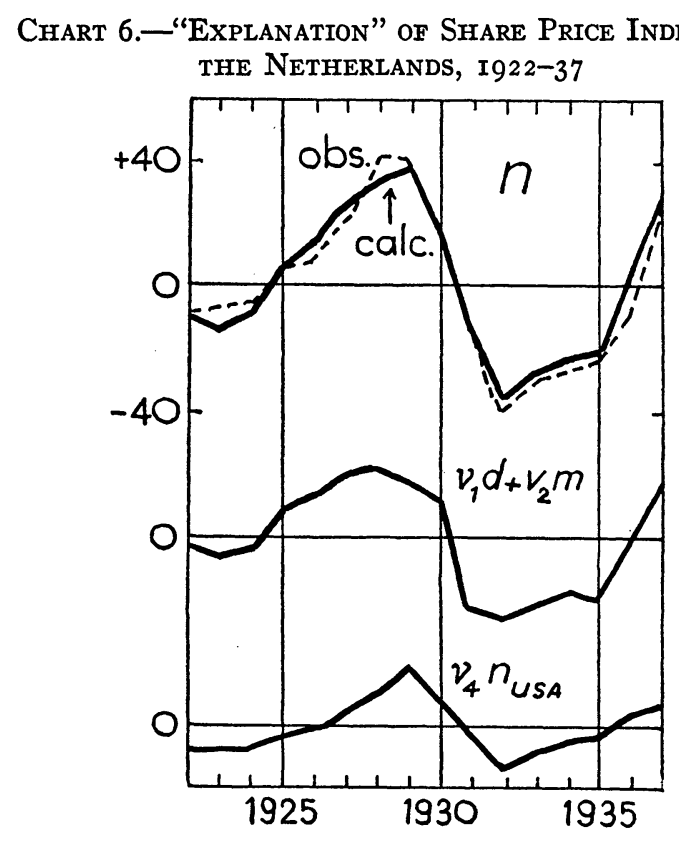

United States, when the well-known and unprecedented stock-exchange boom developed. There is a tremendous difference between the force of speculation as measured by this coefficient in the case of the United States after the war and all other cases studied. In order of magnitude the next large coefficients are found respectively for the United Kingdom before the war, the United States before the war, and Belgium, whereas almost no trace of a speculative attitude can be found in the cases of Germany and the Netherlands. ${ }^{1}$

Although the results now obtained could be supplemented and refined in many ways, there seems to be hardly any doubt that national differences in this respect are large and are

\footnotetext{
${ }^{1}$ In the case of the Netherlands it may be that speculation based itself on the course of American share prices.
}

somewhat as one would expect them to be. It follows that the great importance attributed to the stock exchange in the explanations of the post-war American business cycle cannot be advanced in the same degree in any explanation of pre-war cycles and of German cycles. It is the purpose of further studies under prep-

Chart 7.- "Explanation" of Share Price Index for THE Netherlands EAST INDIES, I922-37

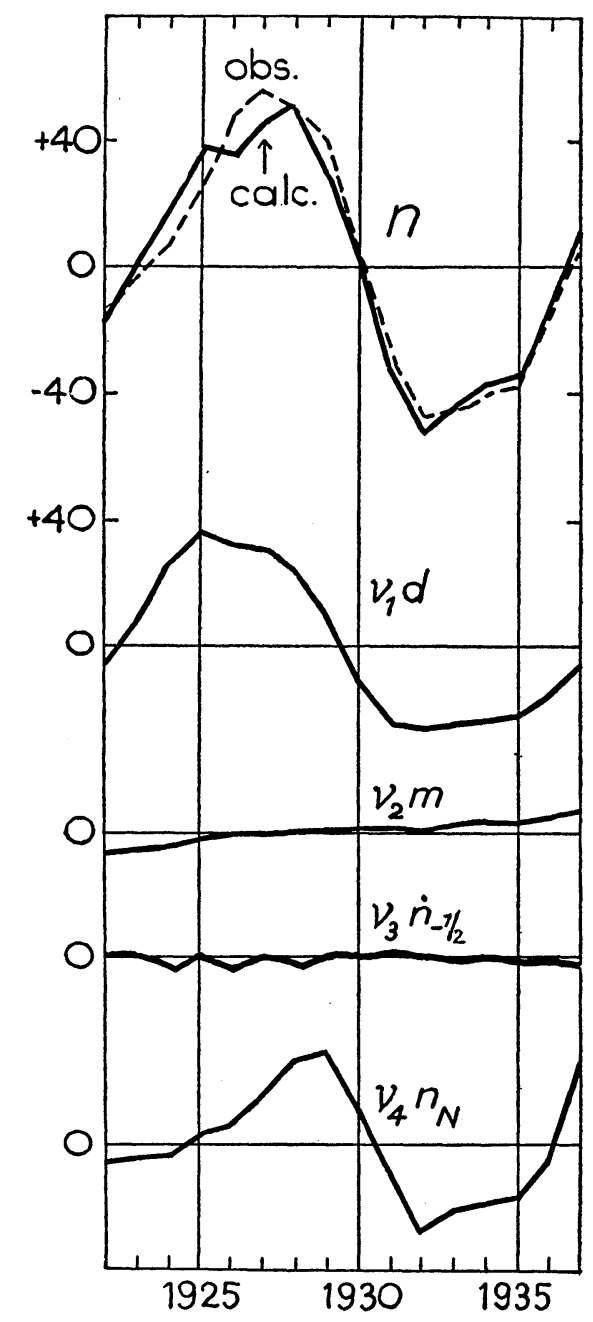

aration to make comparisons of this same type for the other forces found to be active in the business cycle. Apart from the chief conclusion reached, there are some other details that may be mentioned. Looking at the increase in share prices for the United Kingdom toward the end of the nineteenth century, one finds from Chart 4 that this increase can not be explained solely by the heavy fall of interest rates, 
but that the speculative force, embodied in our dynamic law, also yields an important contribution to the explanation. In addition, one general feature of the fluctuations in share prices in the United Kingdom can also be explained by our dynamic law. This feature consists of the rapid and short rise and the rather slow downturn exhibited by these share prices, which is contrary to what is commonly assumed to be the case. From the chart we see that this particular shape of the curves can not be explained by the static forces, i.e., by the influence of dividends and interest rates, but it may be explained by our third term, which in fact makes for the sudden increases in share prices during every boom before the war. 
http://www.jstor.org

\title{
LINKED CITATIONS \\ - Page 1 of 1 -
}

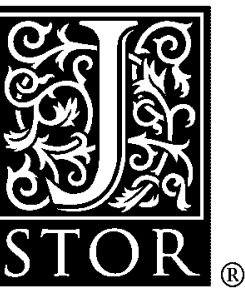

You have printed the following article:

\section{The Dynamics of Share-Price Formation}

\section{$\mathrm{J}$. Tinbergen}

The Review of Economic Statistics, Vol. 21, No. 4. (Nov., 1939), pp. 153-160.

Stable URL:

http://links.jstor.org/sici?sici=0034-6535\%28193911\%2921\%3A4\%3C153\%3ATDOSF\%3E2.0.CO\%3B2-U

This article references the following linked citations. If you are trying to access articles from an off-campus location, you may be required to first logon via your library web site to access JSTOR. Please visit your library's website or contact a librarian to learn about options for remote access to JSTOR.

\section{[Footnotes]}

\author{
${ }^{1}$ The Notions of Horizon and Expectancy in Dynamic Economics \\ J. Tinbergen \\ Econometrica, Vol. 1, No. 3. (Jul., 1933), pp. 247-264. \\ Stable URL: \\ http://links.jstor.org/sici?sici=0012-9682\%28193307\%291\%3A3\%3C247\%3ATNOHAE\%3E2.0.CO\%3B2-0
}

NOTE: The reference numbering from the original has been maintained in this citation list. 